\title{
Amlodipine induced Gingival Overgrowth
}

\author{
Dr. Deepa Aryal, ${ }^{1}$ Dr. Kripa Shahi, ${ }^{1}$ Dr. Surendra Man Shrestha ${ }^{1}$ \\ ${ }^{1}$ Department of Periodontology and Oral Implantology, \\ People's Dental College and Hospital, Kathmandu, Nepal.
}

\begin{abstract}
Gingival overgrowth caused by drug is a well-documented unwanted side effect and mostly caused by Nifedipine. Newer generation calcium channel blocker, amlodipine, has been used with the increasing frequency to overcome the adverse effect of first and second generation dihydropyridine derivatives of Calcium Chanel Blocker. The pathogenesis of gingival enlargement is uncertain and the treatment is still largely limited to the maintenance of an improved level of oral hygiene and surgical removal of the overgrowth tissue. This article reports the amlodipine induced gingival enlargement and its treatment in a 60 years old hypertensive female patient.
\end{abstract}

Keywords: Amlodipine; DIGO; gingivectomy.

\section{INTRODUCTION}

Gingival enlargement/ gingival hyperplasia/hypertrophic gingivitis is an increase in the size of gingiva. Many types of gingival enlargement have been reported and classified on the basis of aetiological factor. The aetiological factors that cause enlargement are chronic inflammation, drug induced gingival enlargement, enlargement associated with systemic condition, neoplastic enlargement etc. Drug induced gingival enlargement is an adverse effect of drugs such as the use of phenytoin, amlodipine, cyclosporine. ${ }^{1}$ Drug-Induced Gingival Overgrowth (DIGO) due to calcium channel blocker may occur when influx of calcium ions across the cell membrane decreases due to reduced membrane permeability and with decreased influx of calcium, the secretory function of affected fibroblastic cells or collagenases production is reduced or inhibited. Thus, increased fibroblastic proliferation and collagen synthesis occurs which gives rise to enlargement. ${ }^{2}$ Amlodipine is a newer long acting calcium channel blocker, a dihydropyridine derivatives prescribed in the patient with hypertension, coronary artery disease, coronary artery spasm,

\section{Correspondence:}

Dr. Deepa Aryal

Department of Periodontology and Oral Implantology, People's Dental College and Hospital, Kathmandu, Nepal. email: aryaldeepa26@gmail.com

\section{Citation}

Aryal D, Shahi K, Shrestha SM, Amlodipine induced Gingival Overgrowth. J Nepal Soc Perio Oral Implantol. 2018;2(1):30-2. cardiac arrhythmias. The incidence of enlargement is $3.3 \%$ in patient of cardiac diseases taking $5 \mathrm{mg} / \mathrm{kg}$ of amlodipine. ${ }^{3}$ This report also describes a hypertensive patient who had extensive gingival hyperplasia in response to the amlodipine and its treatment.

\section{CASE REPORT}

A 60-year-old female patient reported to the Department of Periodontics People's Dental College and Hospital with chief complaint of swelling in the lower front gum for eight months. History revealed that the patient was diagnosed with hypertension five years back and was taking Amlodipine (Tab Amlod 5mg) since then. She noticed the enlargement of her gums in lower anterior region with associated intermittent pain and occasional bleeding. On general examination, the patient was moderately built and nourished. Intraoral examination revealed diffuse lobulated/nodular enlargement of gingiva in lower anterior jaw (Grade 3: Millers classification of drug induced gingival enlargement) involving interdental, marginal and attached gingiva with the presence of pseudo pocket. Spontaneous bleeding (Gingival Index- 3: Loe and Silness), 9mm pocket (Combined pocket) and Grade II mobility in relation to 43 . Plaque score in the patient was 1.6 (Fair: Silness and Loe).

The case was provisionally diagnosed as chronic generalised gingivitis with localised periodontitis in relation to 43, drug induced gingival enlargement in relation to $12,41,42,43,44$, 31,32 , and 33. 
Table 1: Treatment regimen.

\begin{tabular}{|l|l|}
\hline Phases & \multicolumn{1}{c}{ Therapy } \\
\hline $\begin{array}{l}\text { Initial phase } \\
\text { 1st week }\end{array}$ & $\begin{array}{l}\text { History taking, examination, scaling and root planing, chlorhexidine mouth rinse } 0.2 \% \text { in every morning and even- } \\
\text { ing for 2 weeks, antibiotic coverage for 1 week, drug substitution Labetalol } 100 \text { mg twice daily }\end{array}$ \\
\hline 2nd week & Evaluation of phase I, Root Planing and Curettage done in relation to 43 \\
\hline Surgical phase (4th week) & Gingivectomy 41,42,43,31,32,33,44 done under local anesthesia. \\
\hline Maintenance phase & Evaluation, monitoring and scaling \\
\hline
\end{tabular}

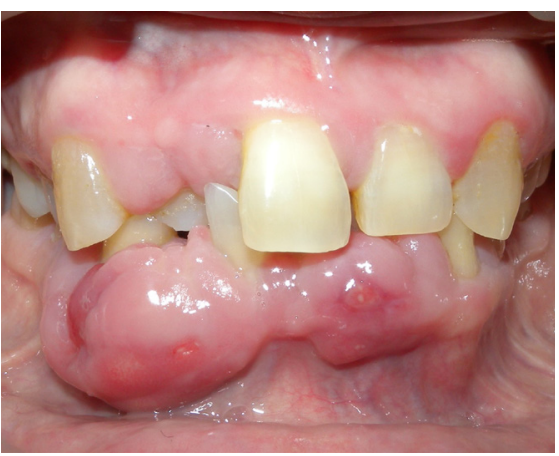

Figure 1: Clinical photograph showing frontal view.

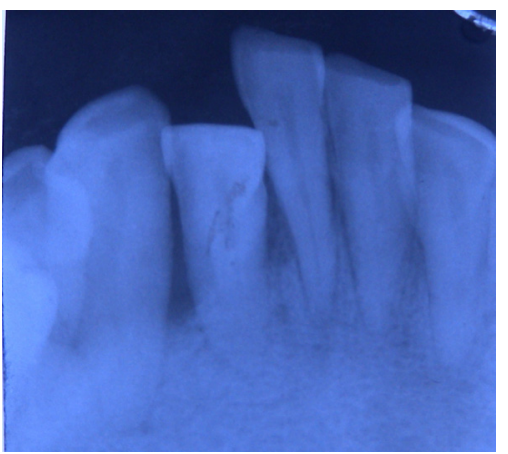

Figure 2: Radiographic photograph showing the bone loss in relation to 43 .

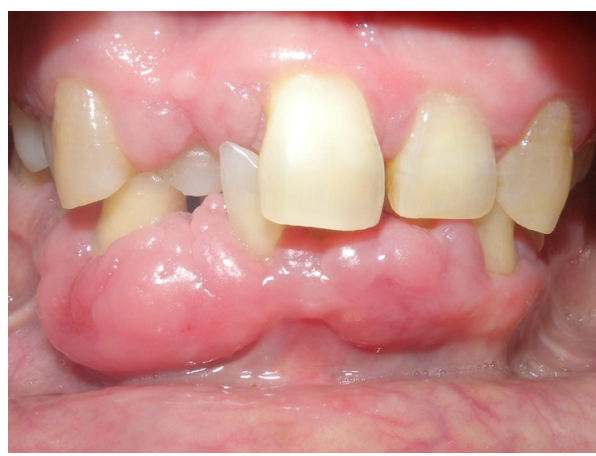

Figure 3: Clinical photograph showing the gingival enlargement after professional cleaning.

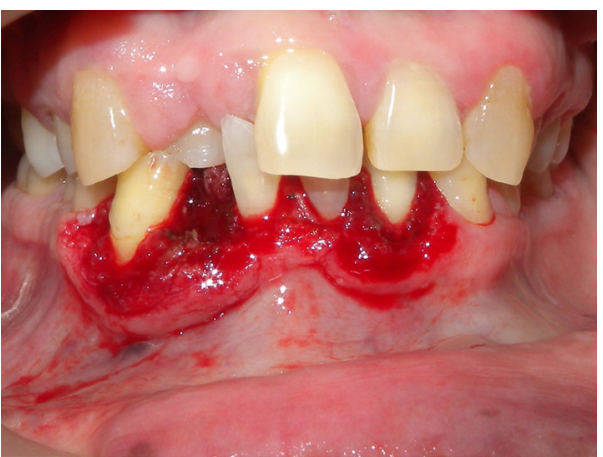

Figure 4: Clinical photograph showing gingivectomy using Scalpel.
Gingivectomy procedure was done after pocket in each tooth surface were explored with a periodontal probe and marked with pocket marker. Bard- parker knives \#15 was used for incision on the facial aspect apical to the point marking and was directed coronally (external bevel) to a point between the base of pocket and crest of alveolar bone. Pocket present in 43 was curetted, root planned. Electrocautery has been used to control the hemorrhage during the treatment. Then the surgical area was covered with periodontal pack.

\section{DISCUSSION}

Amlodipine is a calcium channel blocker that is structurally similar but with different pharmacokinetics compared to the Nifedipine. ${ }^{4}$ The enlargement caused by chronic medication of Nifedipine is $6.3 \%$ which is more than that of amlodipine. ${ }^{4}$ It also shows inflammatory feature and has three times more predilection for male. ${ }^{4}$ Similar male preponderance of DIGO has also been reported by Seymour et al 2000.5 Amlodipine

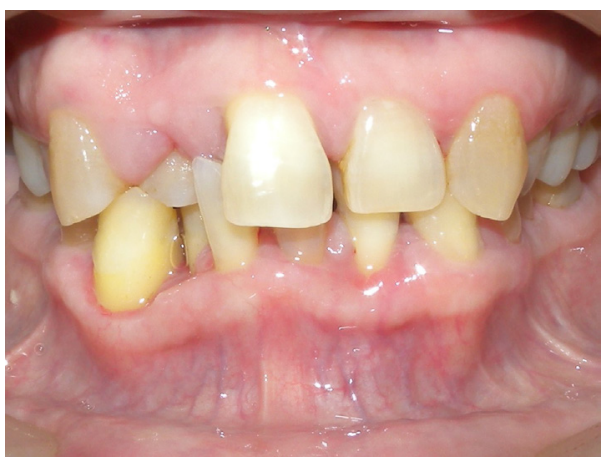

Figure 5: Clinical photograph showing 1 month follow up after gingivectomy.

Associated Gingival Enlargement (AAGE) generally occurred within the three months of initiation of drug at the dose of $10 \mathrm{mg} /$ day but in the above case the enlargement was noticed after two years at the dose of $5 \mathrm{mg} /$ day. ${ }^{6,7}$ In a review, drug induced gingival enlargement is multifactorial, involving several other factors like age, genetic predisposing, plaque induced inflammatory and immunological changes. ${ }^{7}$ The treatment for drug induced enlargement consists of stopping the offending drug after physician consultation, professional cleaning for plaque control and oral hygiene measures. If the enlargement persists even after drug switching then those cases need to undergo gingivectomy with or without flap surgery. ${ }^{8}$ In our case gingivectomy was done to control the plaque and histology showed the presence of hyperplastic epithelium with the interconnected long and thin rete ridges proliferating towards the connective tissue with the underlying stroma which diffused moderately dense inflammatory cells mainly lymphocytes and plasma cells, 
plump of fibroblast and dense collagenous stroma which are the characteristic feature of hyperplastic gingiva. ${ }^{9}$ Some investigator believe that inflammation is a perquisite for the development of the enlargement and hypothesised that in non-inflamed gingiva, fibroblast are less active or quiescent even in the presence of drug. ${ }^{10}$ This case report illustrates amlodipine induced gingival hyperplasia that causes plaque control problem, affects mastication and cause aesthetic problem in a patient. Gingivectomy was the treatment of choice that helped to overcome these problems. Patient education and proper practice of oral hygiene everyday plays a vital role in future maintenance.

\section{ACKNOWLEDGEMENT}

I would like to express sincere gratitude to Dr. Kishor Bhandari, Dr. Sujaya Gupta, Dr. Lalith Vivekanand (M.R Amedkar Dental College and Hospital, India), Dr. Ameena Pradhan and Dr. Shreeya Aryal for their generous help.

\section{REFERENCES}

1. Banthia R, Jain P, Banthia P, Belludi S, Jain AK. Amlodipine- induced gingival overgrowth: a case report. J Mich Dent Assoc. 2012 Sep;94(9):48-51.

2. Chaubal T, Bapat R. Mulberry-Shaped Gingival Overgrowth Induced by Amlodipine and Cyclosporine. Am J Med Sci. 2017 Dec;354(6):e13.

3. Jorgensen MG. Prevalence of amlodipine-related gingival hyperplasia. J Periodontol. 1997 Jul;68(7):676-8.

4. Ellis JS, Seymour RA, Steele JG, Robertson P, Butler TJ, Thomason JM. Prevalence of gingival overgrowth induced by calcium channel blockers: a community-based study. J Periodontol. 1999 Jan; 70(1):63-7.

5. Seymour RA, Ellis JS, Thomason JM. Risk factors for drug-induced gingival overgrowth. J Clin Periodontol. 2000 Apr; 27 (4):217-23.

6. Tripathi AK, Mukherjee S, Saimbi CS, Kumar V. Low dose amlodipine-induced gingival enlargement: A clinical case series. Contemp Clin Dent. 2015;6(1):107-9.

7. Seymour RA, Thomason JM, Ellis JS. The pathogenesis of drug-induced gingival overgrowth. J Clin Periodontol. 1996 Mar; $23(3$ Pt 1):165-75.

8. Mavrogiannis M, Ellis JS, Seymour RA, Thomason JM. The efficacy of three different surgical techniques in the management of druginduced gingival overgrowth. J Clin Periodontol. 2006 Sep; 33(9):677-82.

9. Cyclosporin, nifedipine, and gingival hyperplasia. - PubMed - NCBI [Internet]. [cited 2018 Mar 8]. Available from: https://www.ncbi.nlm. nih.gov/pubmed/2888958

10. Hassell TM, Page RC, Lindhe J. Histologic evidence for impaired growth control in diphenylhydantoin gingival overgrowth in man. Arch Oral Biol. 1978; 23(5):381-4. 